\title{
Há sempre o que ensinar, há sempre o que aprender: como e por que educação matemática na terceira idade?
}

\author{
There is always something to teach, there is always something to learn: \\ how and why should we teach mathematics to senior people?
}

\author{
Luciano Feliciano de Lima* \\ ORCID iD 0000-0001-9055-0791 \\ Miriam Godoy Penteado** \\ ORCID iD 0000-0003-0458-275X \\ Guilherme Henrique Gomes da Silva ${ }^{* * *}$ \\ ORCID iD 0000-0002-4166-2663
}

\begin{abstract}
Resumo
A temática deste artigo está relacionada ao desenvolvimento de ações educativas com pessoas idosas, mais especificamente referentes à Educação Matemática, promovidas a partir da extensão universitária. Considera-se que a frequência deste público em ambientes educativos pode contribuir com a manutenção e com o desenvolvimento de aspectos cognitivos fundamentais para a autonomia dos mesmos. Além disso, a participação nesses espaços pode favorecer transformações nos aspectos físico, social e psicológico, potencializando a autoestima. Discutimos resultados de uma pesquisa cujo objetivo foi compreender possíveis formas de promover tais ações e oferecer subsídios para uma reflexão a respeito de suas contribuições para o público na terceira idade. A produção de dados ocorreu no âmbito de uma ação extensionista intitulada Conversas sobre Matemática com pessoas idosas. As informações foram registradas em entrevistas, fotografias e diário de campo. A análise indicou uma participação ativa das senhoras e senhores que se revelou da seguinte forma: a) interesse em comentar o assunto trabalhado; b) persistência para realizar as tarefas por conta própria; c) argumentação das ideias apresentadas; d) compartilhamentos com pessoas de fora do grupo. Tal participação trouxera contribuições que se manifestaram como: a) melhoria dos aspectos cognitivos; b) oportunidade de interação social; c) possibilidade de se conhecer novos assuntos relacionados à Matemática.
\end{abstract}

Palavras-chave: Diálogo. Educação de Idosos. Educação Matemática.

\begin{abstract}
* Doutor em Educação Matemática pela Universidade Estadual Paulista (Unesp). Professor da Universidade Estadual de Goiás (UEG), Morrinhos, GO, Brasil. Endereço para correspondencia: Rua 261 B, n. 500, Panoramic Residence, apto 3202, Setor Leste Universitário, Goiânia, GO, Brasil, CEP: 74610-270. E-mail: 7lucianolima@gmail.com.

** Livre Docente em Educação Matemática pela Universidade Estadual Paulista (Unesp). Professora do Departamento de Educação Matemática, IGCE, da Universidade Estadual Paulista (Unesp), Rio Claro, São Paulo, Brasil. Endereço para correspondencia: Av. 24-A, 1515, Bela Vista, 13506-900, Rio Claro, São Paulo, Brasil. Email miriam-godoy.penteado@unesp.br.

**** Doutor em Educação Matemática pela Universidade Estadual Paulista (Unesp). Docente do Programa de PósGraduação em Educação e do Departamento de Matemática da Universidade Federal de Alfenas (UNIFAL-MG), Alfenas, MG, Brasil. Endereço para correspondencia: Rua Gabriel Monteiro da Silva 700, Centro, Alfenas, MG, Brasil, CEP: 37130-001. E-mail: guilhermehgs2@gmail.com.
\end{abstract}


This paper is related to the development of educative actions with senior people. More specifically, it refers to the Mathematical Education promoted in the space of university extension activities. It is considered that the engagement of senior people in educational environments can contribute to the maintenance and development of cognitive aspects, which are fundamental to their autonomy. In addition, participation in these environments can favor changes in their physical, social, and psychological aspects, enhancing their self-esteem. In this paper, we discuss results of a research which aimed at understanding possible ways to promote such educational actions and to providing elements to a reflection about its contributions to senior people. Data production occurred within the project Conversation about Mathematics with Senior People. Data were collect through interviews, photos, and notes in a research notebook. Data analysis reveals an active engagement of the women and men in the project as well as provides some indication about contributions to the senior people. About their engagement, we considered: a) their interest in discussing the subjects during the meetings; b) their persistence to perform mathematics tasks on their own; c) their argumentation about the ideas showed; and d) their movement of sharing the activities with other people who were not participating in the project. In relation to contribution to senior people, we considered manifestations that expressed: a) improvement of cognitive aspects; b) opportunity for social interaction; and c) the possibility of learning new subjects related to Mathematics.

Keywords: Dialogue. Education for Seniors. Mathematics Education.

\section{Introdução}

O número de indivíduos com mais de 60 anos de idade tem aumentado progressivamente no Brasil. Dados do Instituto Brasileiro de Geografia e Estatística (IBGE, 2018a) projetam que, em 2060, a população idosa representará um terço de toda população brasileira. Em 2017, o país possuía cerca de 30,2 milhões de pessoas nesta faixa etária, representando 14,6\% de toda população (IBGE, 2018b). Em contrapartida, o número de crianças de 0 a 14 anos de idade está diminuindo e, pelas projeções de IBGE (2018a), em 2060, teremos mais idosos do que crianças no país, o que mostra um sinal claro de envelhecimento da população.

Se compararmos com anos anteriores, como, por exemplo, 1940, cuja média da expectativa de vida dos brasileiros, mulheres e homens, era de 45,5 anos, temos um aumento significativo em quase um quarto de século, uma vez que, nos anos 2000, a expectativa de vida chegou aos 70,4 anos (IBGE, 2013). É importante lembrar que a média da expectativa de vida não ocorre de maneira homogênea no Brasil. Vivemos em um país continental, com diferenças regionais, culturais, sociais, econômicas, dentre outras. Consequentemente, estados distintos apresentam diferentes expectativas de vida. Por exemplo, no ano de 2015, estatísticas mostraram que o Estado de Santa Catarina possuía a maior expectativa de vida, dentre todos os estados brasileiros, com 78,7 anos. Em contrapartida, o estado do Maranhão teve a menor média, para ambos os sexos, com 70,3 anos. O estado de Alagoas apresentou a menor média de expectativa de vida para os homens, com 66,5 anos, e Roraima teve a menor média de expectativa de vida para mulheres, com 74 anos (IBGE, 2016).

A desigualdade na expectativa de vida não é exclusividade da relação entre os diferentes estados. Em uma mesma cidade também é possível que ocorram diferenças significativas. 
Conforme o relatório da organização "Rede Nossa São Paulo", na cidade de São Paulo os residentes em bairros mais ricos têm expectativa de vida muito mais elevada quando comparada aos habitantes de bairros economicamente menos favorecidos. Por exemplo, enquanto no bairro Alto dos Pinheiros a expectativa de vida é de 79,67 anos, no bairro Cidade Tiradentes esta é de apenas 53,85 anos (MAPA DA DESIGUALDADE 2016, 2016). Mesmo com estas ressalvas, considerando-se de forma geral a média de toda a população brasileira, a ampliação da expectativa de vida será ainda maior em 2050, chegando aos 81,3 anos (IBGE, 2013).

Esses números nos mostram que os brasileiros estão vivendo mais. Entretanto, estaríamos buscando uma vida com mais qualidade? De acordo com a divisão de Saúde Mental da Organização Mundial de Saúde (OMS), a qualidade de vida está relacionada com a percepção do indivíduo no que tange a sua vida, à posição que ocupa no contexto cultural em que está inserido e em relação aos sistemas de valores em que vive, bem como às suas expectativas, padrões e preocupações (FREITAS; PY, 2006). Já para a American Psychological Association (APA), uma boa qualidade de vida está relacionada aos seguintes aspectos: bemestar emocional, material e físico; envolvimento em relações interpessoais; oportunidades para desenvolvimento pessoal; exercer seus direitos e fazer escolhas de estilo de vida autodefinidos; participação na sociedade (VANDENBOS, 2010).

Com Goldemberg (2013), entendemos a responsabilidade, assim como a importância, de cada indivíduo construir uma "bela velhice" para si. Considerando "bela velhice" como algo associado a um "belo projeto de vida", assim sendo, individual e subjetivo. Poderíamos entender a bela velhice como uma inquietação sobre possibilidades para se conquistar um envelhecimento bem-sucedido e com qualidade de vida. Este tema tem ganhado relevância desde a década de 1970, consequência do início da tendência de aumento no número de pessoas idosas. Por este motivo, os aspectos relacionados ao bem-estar físico, psicológico e social de pessoas idosas passaram a fazer parte da gestão de políticas públicas em saúde, educação, trabalho e seguridade social, assim como de pesquisas científicas de diversos países (NERI, 2001).

As ações visando melhoria da qualidade de vida de pessoas idosas podem ser realizadas de diferentes formas e abordando diferentes assuntos como, por exemplo, aqueles relacionados à educação. De acordo com literatura sobre essa temática, frequentar espaços educativos pode resultar em ganhos importantes para a qualidade de vida como, por exemplo, ampliar a rede de amizades. Além disso, contribuições como maior autonomia física e vida social mais diversificada favorecem a saúde psicológica das pessoas (ALVES, 2007; BRANCO, 2007; 
CACHIONI; NERI, 2004; CACHIONI; PALMA, 2006; DIAS, 2010; LARA, 2010; LIMA, 2015; PEREIRA, 2011/2012; PINHEIRO, 2009).

O tempo da velhice pode ser um período da vida em que se está livre de responsabilidades tais como o trabalho, os filhos e outros afazeres. Essa liberdade pode propiciar aos idosos mais momentos para reflexões sobre a vida, de forma a compreenderem que podem continuar sendo "atuantes, curiosos, capazes de correr risco, transformadores, [...] aptos para intervir no mundo, mais do que puramente a ele [se] acomodar" (FREIRE, 2000, p. 42).

A participação de idosos em ambientes educativos mostra-se importante para que eles continuem, por exemplo, se sentindo integrados socialmente, visto que aprender coisas novas pode contribuir com a qualidade de vida. Nesse artigo, concentramos nossa atenção em ações educativas relacionadas à Matemática. Apresentamos resultados de uma pesquisa que buscou explorar como o envolvimento com tarefas matemáticas podem se constituir em uma possibilidade para a terceira idade. No que segue, apresentamos a organização de uma ação extensionista, assim como a produção e registros dos dados para a pesquisa aqui discutida. Por fim, discutimos aspectos que apontam uma participação ativa, das senhoras e senhores, na ação extensionista e possíveis contribuições de tal participação.

\section{A ação extensionista Conversas sobre Matemática com pessoas idosas}

Conversas sobre Matemática com pessoas idosas, ou somente Conversas, faz parte do conjunto de ações do Laboratório de Ensino de Matemática (LEM), do Departamento de Educação Matemática da Universidade Estadual Paulista (Unesp), Câmpus de Rio Claro-SP, e tem como objetivo reunir diferentes grupos para conversar sobre Matemática e Educação Matemática. Em particular, a ação Conversas, objeto de discussão deste artigo, foi planejada em conjunto com pesquisadores do Programa de Atividade Física para Pacientes com doença de Parkinson (PROPARKI), do Departamento de Educação Física desta mesma instituição. Ela foi articulada com a ação AtivaMente, que é uma atividade do PROPARKI relacionada ao desenvolvimento da cognição de pessoas com Parkinson.

Para atuar em sintonia com as atividades desenvolvidas na ação AtivaMente, e levandose em conta um trabalho envolvendo pessoas com Parkinson, a equipe do LEM planejou atividades visando a manipulação de objetos como, por exemplo, o Tangram, os Blocos Lógicos, os Poliedros de Platão, a Faixa de Moebius, dentre outros. Esses recursos foram utilizados em tarefas para estimular as funções cognitivas dos participantes, por meio de uma 
abordagem dialógica e investigativa, como discutidas por Skovsmose (2011). A utilização de materiais manipuláveis, como sugerem Santos e Sá (2000), foi importante porque consideramos que poderiam tornar as tarefas matemáticas mais atraentes aos idosos, para além de estimularem aspectos cognitivos e físicos.

Cabe dizer que a elaboração das tarefas foi um desafio considerável para a equipe, uma vez que o nível de familiaridade dos participantes com a Matemática escolar era bem heterogêneo. No grupo tínhamos dois extremos: enquanto alguns nunca haviam frequentado a escola, outros participantes possuíam diploma de curso superior. No intervalo entre esses extremos havia pessoas com Ensino Fundamental incompleto, Ensino Fundamental completo e Ensino Médio. Devido a esta diversidade, tomamos o cuidado de não propor algo demasiado difícil ou, ao contrário, algo que não interessasse por causa de sua simplicidade. É por este motivo que, ao iniciarmos uma tarefa matemática com este grupo, sugeríamos uma situação problema ou jogos.

Pretendíamos gerar um envolvimento no grupo para que os idosos pudessem manifestar seus pontos de vista sobre o assunto abordado. Cabe reforçar que eles apenas expunham seus pontos de vista se quisessem compartilhar com os demais suas compreensões e/ou vivências acerca do tema abordado. Nossa preocupação era com a constituição de um ambiente em que as pessoas se sentissem à vontade para se manifestarem ou para ficarem caladas, ouvindo os demais participantes ${ }^{1}$. Com um ambiente propício a ouvir o outro, tanto por parte das senhoras e senhores quanto da equipe da ação Conversas, não houve percepção de constrangimento dos participantes, nem nos encontros do grupo, tampouco nas entrevistas. Um indício, a ser destacado, é o fato de que os idosos não deixavam de participar dos encontros, embora não houvesse qualquer obrigação nesse sentido. Cabe destacar que o envolvimento das senhoras e senhores nas atividades matemáticas teve influência significativa do estímulo dos profissionais do PROPARKI para que os idosos participassem de todas as ações, físicas e cognitivas, como maneira de retardar o avanço do Parkinson.

A ação Conversas pautou-se em uma concepção crítica de educação, realizada por meio de uma abordagem dialógica e investigativa (ALRØ; SKOVSMOSE, 2015; FREIRE, 2011). Para desenvolvê-la, nos fundamentamos na concepção de educação dialógica de Paulo Freire, para quem um diálogo não é uma interação de “A para B ou de A sobre B, mas de A com B, mediatizados pelo mundo. Mundo que impressiona e desafia a uns e a outros, originando visões ou pontos de vista sobre ele" (FREIRE, 2011, p. 116). Entendemos, com Freire (2011), que em 
um ambiente dialógico não é possível impor algo para o outro. Pelo contrário, há a necessidade de reflexão sobre as ideias e ações. Neste sentido, concordamos que conhecer significa

\begin{abstract}
construir percepções, elaborar outros sentidos, situar-se de modo novo diante das coisas e dos outros. Em outros termos, conhecer constitui uma ação de incorporação, da qual resulta, necessariamente, uma nova performance do sujeito aprendente, o que só é possível mediante sua cumplicidade, mediante seu engajamento (BOUFLEUER, 2010, p. 76).
\end{abstract}

Entender o conhecimento dessa forma nos leva a assumir uma postura de colaboração com o outro para a produção de novos sentidos sobre algo. Assim, os homens "em suas permanentes relações com a realidade, produzem, não somente os bens materiais, as coisas sensíveis, os objetos, mas também as instituições sociais, suas ideias, suas concepções." (FREIRE, 2011, p. 128). Com Paulo Freire entendemos os seres humanos, independentemente de sua idade, como sujeitos de conhecimento. Por isto, planejamos e realizamos as tarefas matemáticas com as senhoras e os senhores do grupo, buscando estimular, nelas e neles, uma compreensão de si como seres que podem produzir, coletiva e colaborativamente, conhecimentos sobre os mais variados assuntos, incluindo a Matemática. Para isso, buscamos estabelecer um sentimento de confiança entre os envolvidos.

Este sentimento de confiança poderia favorecer uma abertura para se mostrar, ou seja, para dizer o que se pensava sobre um assunto, sem correr o risco de ser criticado de forma destrutiva. Nesse sentido, a confiança estabelecida entre os membros do grupo poderia estimular a curiosidade sobre a temática em questão, que seria "compensada e gratificada pelo êxito da compreensão alcançada" (FREIRE, 1998, p. 134). Buscamos estimular os participantes a continuarem em uma busca permanente pelo entendimento dos assuntos matemáticos por meio de questionamentos, como os sugeridos por Skovsmose (2000), do tipo "o que acontece se...?".

Cabe considerar que o sucesso dessa dinâmica dependia bastante do responsável por conduzir o grupo. Por isso fazíamos, em todos os momentos possíveis, questionamentos pertinentes para estimular a reflexão dos participantes sobre a tarefa matemática em questão. Convidávamos a todas e todos a explicarem, em suas palavras, as situações apresentadas. Sugeríamos que pensassem em como resolver um problema e testassem as possíveis soluções. Também pedíamos para que justificassem as suas ideias, sempre que possível, por meio de argumentações matemáticas (PONTE; BROCARDO; OLIVEIRA, 2015).

Um exemplo foi o trabalho com a Faixa de Moebius. Nesse dia, iniciamos a atividade questionando se os idosos sabiam o que era um cilindro e se poderiam fornecer um exemplo. Lata de óleo e de milho arredondadas, canos, dentre outros, foram os objetos citados. Em 
seguida os participantes foram convidados a construírem um cilindro com o material disponível nas mesas. Na sequência, era a vez de se construir a Faixa de Moebius. As senhoras e os senhores não a conheciam e colocaram a "mão na massa" construindo a faixa e realizando as experimentações conforme as orientações fornecidas por nós.

Após cada participante construir sua faixa, auxiliados pela equipe do LEM, foram convidados a compararem o cilindro e a Faixa de Moebius. Questionou-se quantos lados teria cada um deles e eles se manifestaram dizendo "dois: o lado de dentro e o de fora". $\mathrm{Na}$ continuidade, cada um recebeu uma caneta hidrográfica para contornarem, tanto o cilindro quanto a Faixa, visando explorar mais a questão sobre o "dentro e fora" daqueles objetos. Já haviam dito que o cilindro tinha "um lado de dentro e outro de fora", agora seria o momento de fazer a pergunta em relação a Faixa de Moebius: “Quantos lados vocês acham que tem a faixa?”. Um senhor respondeu que tinha dois, outro senhor disse que tinha três, uma senhora disse que tinha um e algumas pessoas disseram que não sabiam. Não dissemos quem estava certo ou errado, ou qual seria a resposta. Pelo contrário, estimulamos que tirassem suas próprias conclusões contornando a faixa com uma caneta, assim como haviam feito com o cilindro.

Após todos os participantes realizarem o que havia sido pedido, questionamos: "O que vocês perceberam quando contornaram a faixa com a caneta?”. A Sra. Ju $(60)^{2}$ respondeu: “ $A$ linha se encontrou" e a Sra. Sueli (58) concordando disse: "com a minha aconteceu a mesma coisa". É possível notar que essas participantes não tiraram uma conclusão sobre o que significava as linhas se encontrarem. Responderam o que aconteceu ao contornar a faixa com uma caneta, mas faltava refletir sobre o que isso significava. Por isso, continuamos perguntando: "Como assim, a linha se encontrou?" Essa pergunta tinha o intuito de fazer com que os presentes refletissem sobre o que estavam fazendo. Então a Sra. Ju (60) respondeu: “Ué, o final da linha se encontrou com o começo da linha que eu desenhei”. Insistimos com a pergunta: “O que isso significa?” Então, ela respondeu: “Acho que isso significa que essa faixa só tem um lado" (Diário de Campo, Conversas, 2015).

Não dissemos se ela estava certa ou errada, perguntamos aos demais membros do grupo se concordavam com a resposta da Sra. Ju (60). Alguns disseram que ela estava certa e outros não se pronunciaram; finalmente, confirmamos que a resposta dela estava correta: "a faixa de Moebius só tem um lado, e confirmamos isso, quando contornamos com a caneta e ofinal da linha tracejada se encontrou com seu início" (Diário de Campo, Conversas, 2015). As Figuras 1 e 2 ilustram os participantes nesta atividade.

\footnotetext{
${ }^{2}$ Ao nome fictício do participante segue um número entre parênteses, este número indica a idade da pessoa à época do desenvolvimento da ação e das entrevistas.
} 


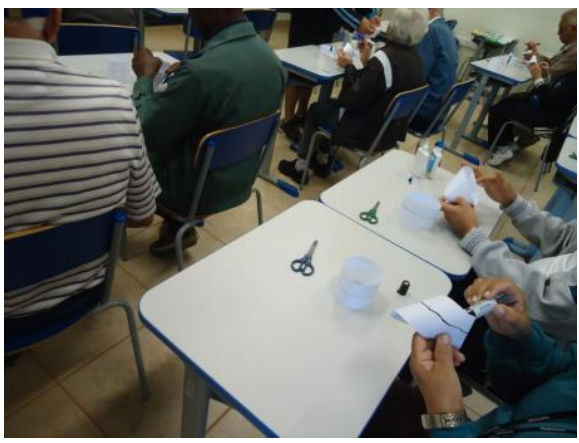

Figura 1 - Atividade com a faixa de Moebius. Fonte: Elaborado pelos autores (2015).

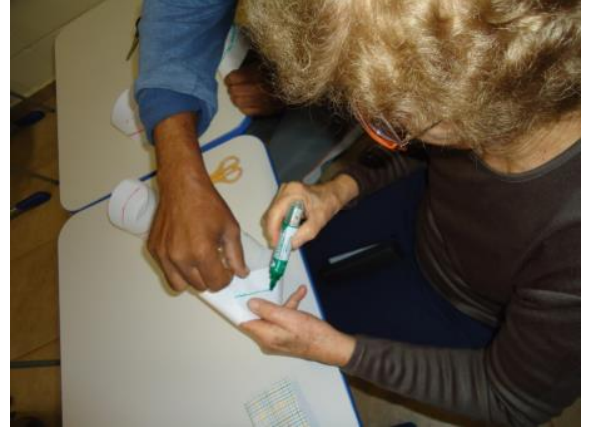

Figura 2 - Senhora sendo auxiliada por um colega. Fonte: Elaborado pelos autores (2015).

Entendemos que incentivar a participação foi uma condição necessária para promover o engajamento de todos. Na elaboração das tarefas, sempre nos preocupamos com o envolvimento dos participantes, desde a escolha do assunto a ser trabalhado até a realização da atividade pelo grupo. Os temas foram inicialmente sugeridos pelos organizadores, mas, com o passar do tempo, os participantes começaram a fazer indicações de assuntos de Matemática que gostariam de discutir durante as Conversas. Por exemplo, Teorema de Pitágoras e funções das teclas da calculadora.

Visando favorecer que todos realizassem/participassem, nos preocupamos, por exemplo, em aumentar o tamanho das letras nas fichas com as tarefas. Com a idade avançada, grande parte do grupo tinha dificuldade para ler textos com fontes pequenas. Igualmente, prestamos atenção à maneira de nos dirigir aos idosos no ambiente da ação Conversas, falávamos mais pausadamente e em um tom mais alto, com o intuito de que todos ouvissem o que estava sendo dito. Para a realização das tarefas, os participantes foram organizados em pequenos grupos. Tais arranjos visavam estimular a participação, facilitar a interação entre eles e com a equipe do LEM. Ao final de cada encontro da ação Conversas a equipe responsável se reunia para avaliar o que havia ocorrido no dia e planejar os próximos encontros, tendo sempre como objetivo a satisfação dos participantes. Com essa dinâmica, não houve nenhuma desistência ligada à recusa em desenvolver as atividades matemáticas. As poucas desistências ocorreram por questões de saúde dos participantes. Na sequência tratamos da metodologia adotada para a pesquisa.

\section{Registro e organização dos dados}

Os encontros realizados na ação Conversas foram quinzenais, com uma hora de duração, e ocorreram durante um ano acadêmico. O grupo era formado por vinte pessoas, todas com Parkinson, sendo que oito aceitaram o convite para serem entrevistadas posteriormente. A 
Tabela 1 apresenta os participantes. Além das entrevistas, houve um diário de campo e o registro da realização das tarefas por meio de fotografias.

Tabela 1 - Informações sobre os participantes

\begin{tabular}{cccccc}
\hline $\begin{array}{c}\text { Nome escolhido pelo } \\
\text { participante }\end{array}$ & Idade & Sexo & $\begin{array}{c}\text { Anos de } \\
\text { escolaridade }\end{array}$ & $\begin{array}{c}\text { Profissão } \\
\text { exercida }\end{array}$ & $\begin{array}{c}\text { Ano de } \\
\text { diagnóstico do } \\
\text { Parkinson }\end{array}$ \\
\hline Sr. Davi & 67 & Masc. & 11 & Comerciante & 2011 \\
Sr. Epitaciano & 76 & Masc. & 8 & Ferroviário & 2007 \\
Sra. Ju & 60 & Fem. & 15 & Examinadora & 2008 \\
Sr. Luciano & 68 & Masc. & 5 & Comerciante & 2002 \\
Sr. Luís & 64 & Masc. & 3 & Motorista & 2006 \\
Sr. Roberto & 77 & Masc. & 5 & Ferroviário & 2008 \\
Sra. Sueli & 58 & Fem. & 11 & Telefonista & 2005 \\
Sra. Teresa & 80 & Fem. & 0 & Dona de casa & 2005 \\
\hline \multicolumn{5}{c}{ Fonte: Elaborado pelos autores (2015). }
\end{tabular}

Nem tudo o que foi falado durante a ação Conversas, ou nas entrevistas, se constituiu em objeto de análise, afinal, como afirma Duarte (2004, p. 219), "do conjunto do material generosamente oferecido a nós pelos nossos informantes, só nos interessa aquilo que está diretamente relacionado aos objetivos da nossa pesquisa, e é isso que deverá ser objeto de leitura". Lembramos que o objetivo da pesquisa foi compreender possíveis formas de promover ações educativas para pessoas idosas e oferecer subsídios para uma reflexão a respeito de suas contribuições para um público dessa faixa etária. Por esse motivo, nosso interesse estava nos comentários sobre as ideias relacionadas com a tarefa como, por exemplo, a tentativa de compreender o que tinham de fazer, as discussões sobre as possíveis soluções, as perguntas de esclarecimento, dentre outros dessa natureza.

Feita essa opção, tudo o que se mostrou de interesse para a pesquisa foi organizado em pastas de computador para facilitar o acesso posterior. Essa organização foi útil para recuperar os dados, à medida que era percebido o seu potencial e que se tinha em mente aquilo que se pretendia escrever. A manipulação do material em pastas facilitou o manejo dos dados. Como apontado por Bodgan e Biklen (2010), é muito importante para o desenvolvimento da pesquisa organizar o material a ser estudado. Para a análise dos dados produzidos, foram retomados diversas vezes o Diário de Campo [DC], as transcrições das entrevistas [Ent] e as fotografias de cada encontro. Neste processo, buscou-se enfatizar trechos significativos sobre a participação nas tarefas propostas bem como sobre contribuições para um público na terceira idade. Tais registros foram destacados e agrupados nos temas participação e contribuição. É sobre eles que discorremos a seguir. 


\section{Sobre a participação na ação Conversas}

Destacamos aqui aspectos relativos à participação das senhoras e dos senhores na ação Conversas relacionadas à realização das tarefas matemáticas sugeridas. Para isto, consideramos: a) interesse em comentar o assunto trabalhado; b) persistência para realizar as tarefas por conta própria; c) argumentação das ideias apresentadas; d) compartilhamentos para além do espaço do LEM.

Nos encontros buscamos realizar reflexões sobre Matemática, por meio de assuntos variados e com a utilização de materiais manipuláveis a fim de estimular a participação independente dos diferentes graus de escolaridade. Além disso, valorizamos os saberes dos idosos e respeitamos o ritmo de cada um ao esperarmos que todos concluíssem suas tarefas. Em se tratando da realização das tarefas matemáticas pelos idosos, entendemos com Pereira (2009, p. 63) que é necessário "haver um envolvimento total do aluno na busca por um significado pessoal no aprendizado". Por esse motivo, estimulamos o envolvimento dos participantes recorrendo a assuntos curiosos e uso de materiais manipuláveis. Um exemplo foi o estudo da Faixa de Moebius descrita anteriormente.

Isso surtiu efeito, pois as senhoras e os senhores do grupo mostraram interesse em comentar o assunto matemático trabalhado. Por exemplo, o Sr. Roberto (77), durante os encontros, sempre compartilhava suas ideias e dúvidas com a equipe do LEM. Em sua fala, durante uma entrevista, considera que os colegas também estão empenhados nas tarefas, ao afirmar que "as pessoas não estão com pressa de irem embora" (Ent, 2015). Em relação à investigação sobre características da faixa de Moebius, ele diz: "Todo mundo estava querendo falar da faixa" (Ent, 2015).

Comentar sobre a tarefa, construindo e reconstruindo conceitos matemáticos, se mostrou como um momento prazeroso para o grupo. Nesse sentido, a Educação Matemática pode contribuir propiciando uma sensação de bem-estar mental quando estimula questionamentos sobre variados temas e uma consequente defesa de ideias. O Sr. Roberto (77) reforça o fato de se sentir bem, por exemplo, ao conseguir resolver as tarefas matemáticas propostas: " $E$ bom fazer essas coisas da Matemática. É uma sensação muito boa, quando a gente consegue fazer" (Ent, 2015). O estímulo para as senhoras e senhores se interessarem em falar sobre a Matemática se dava a partir de perguntas pela equipe do LEM. Nesse sentido, consideramos importante que se façam perguntas e questionamentos para inspirar os participantes em sua produção de conhecimentos, como defendem Freire e Faundez (2011). Por exemplo, em um 
dos encontros em que trabalhamos com o Teorema de Pitágoras, entregamos uma folha com a figura de um triângulo retângulo com lados medindo $(3,4,5)$, como pode ser visto na Figura 3.

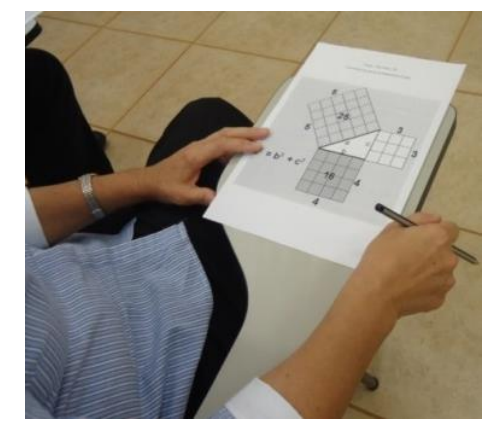

Figura 3 - Teorema de Pitágoras representado em um triângulo retângulo.

Fonte: Elaborado pelos autores (2015).

Logo de início, um senhor diz "a soma dos quadrados dos catetos é o quadrado da hipotenusa" (Diário de Campo, Conversas, 2015), como algumas pessoas não sabiam disso, questionamos se seria verdade e foram orientados a fazerem os cálculos para verificar. Feitos os cálculos, a senhora Ju (60) fez a seguinte consideração: "Na figura [Figura 3] a área do quadrado maior [cujo lado correspondia à hipotenusa] é igual a soma das áreas dos quadrados menores [cujos lados correspondiam aos catetos]" (Diário de Campo, Conversas, 2015). Perguntamos se isso continuaria valendo para outros valores como, por exemplo, ao multiplicarmos as medidas dos lados do triângulo por 2. Visávamos, com esta pergunta, a manutenção do envolvimento das senhoras e dos senhores com a investigação, fato que realmente aconteceu. Interferir, colocando um novo dado na situação estudada, visa encorajar uma postura investigativa (ALRØ; SKOVSMOSE, 2015).

A vontade de participar também pode ser percebida na persistência para realizar as tarefas por conta própria. Por exemplo, durante a entrevista, o Sr. Davi (67) compartilha:

Quando eu cheguei em casa, logo depois da aula, eu não sabia exatamente como montar o quebra-cabeça [quebra-cabeça envolvendo o Teorema de Pitágoras] no quadrado maior; por isso, montei os quadrados menores, um quadradinho azul e um quadradinho amarelo [para facilitar a visualização, montou-se os quadrados menores com cores diferentes]. E, então, pensei: e agora, como faço para resolver? E fui insistindo até conseguir montar no quadrado maior. Fiz isso em casa. O teorema de Pitágoras eu lembro de ter feito na escola e minha professora escrevia no fim CQD, como queríamos demonstrar, não sei se ainda ensina isso. Eu sei é que consegui montar o quadrado maior. Demonstrei também, eu acho que demonstrei. Não é!? (Ent, 2015).

De acordo com Siedler (2006), o envolvimento de pessoas idosas em atividades educativas se mostra através do desejo deles de se fazer corretamente aquilo que lhes é proposto. Acrescentemos a isso o interesse de fazer a tarefa por si. Afinal, o Sr. Davi (67) evidencia sua persistência para montar o quebra-cabeça do Teorema de Pitágoras. Ele poderia ter copiado a solução do quadro, compartilhada por uma senhora que resolveu o problema durante o encontro 
(Figuras 4 e 5). Contudo, informou que preferiu não olhar para a solução, porque queria resolver o problema por si mesmo.

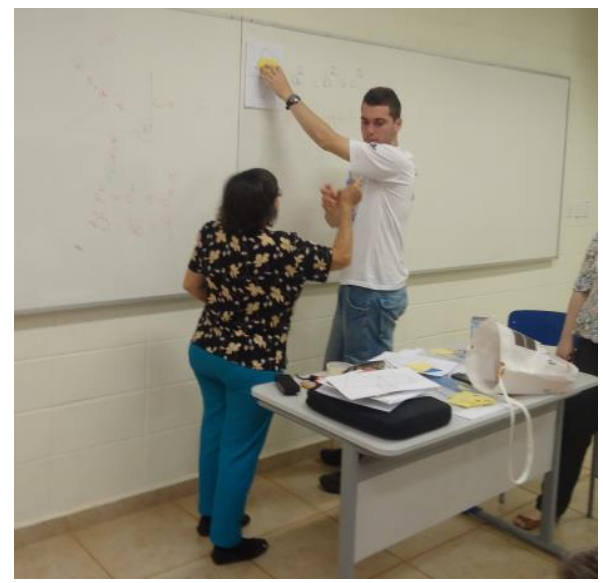

Figura 4 - Senhora explicando sua resolução com auxílio de bolsista do LEM.

Fonte: Elaborado pelos autores (2015).

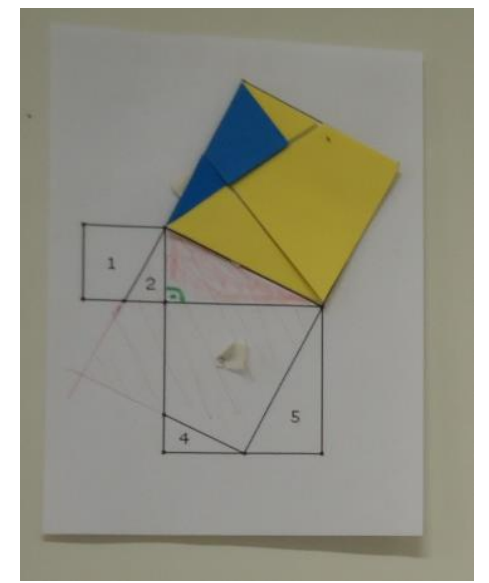

Figura 5 - Resolução do Quebra-Cabeça do Teorema de Pitágoras.

Fonte: Elaborado pelos autores (2015).

A postura persistente deste senhor para conseguir montar o quebra-cabeça do Teorema de Pitágoras, assemelha-se ao que Freire (1998) entende por aprender, ou seja, como "uma aventura criadora, algo, por isso mesmo, muito mais rico do que meramente repetir a lição dada. Aprender para nós é construir, reconstruir...” (p. 77).

A persistência em realizar as tarefas extrapola o ambiente da ação. Isso se evidencia na fala do Sr. Luciano (68). Este senhor comenta que não teve oportunidade em continuar com os estudos, mas destaca sua vontade de aprender:

Eu estou sempre tentando aprender. Como na Matemática, lá na Unesp [ação Conversas], quando você deixa alguma coisa para a gente pensar em casa, eu tento aprender e se não consigo, eu busco ajuda com outras pessoas. E como aprender, se não for na escola? Você precisa buscar, ir atrás, aproveitar o que aprendeu na escola, aí você vai aprimorando. Foi o que aconteceu comigo. A gente vai criando, porque cada um de nós, em certo sentido, vai descobrindo aí, dentro do que você aprendeu, algo que seja melhor para você, para cada um. (Ent, 2015).

O Sr. Luciano (68) evidencia uma postura ativa em seu processo de aprendizagem em que, a partir daquilo que reconhece como aprendido, lança-se, na busca constante, em continuar aprendendo por meio de livros ou de diálogos com outras pessoas. A fala deste senhor nos remete a Freire (2001, p. 260) para quem:

estudar é, em primeiro lugar, um que-fazer crítico, criador, recriador, não importa que eu nele me engaje através da leitura de um texto que trata ou discute certo conteúdo que me foi proposto pela escola ou se o realizo partindo de uma reflexão crítica sobre um certo acontecimento social ou natural e que, como necessidade da própria reflexão, me conduz à leitura de textos que minha curiosidade e minha experiência intelectual me sugerem ou que me são sugeridos por outros.

O Sr. Davi (67) e o Sr. Luciano (68) se mostram como sujeitos preocupados em desenvolver ideias próprias, escolher entre alternativas, decidir caminhos para resolver os 
problemas, implementar ações, argumentar e, nesse processo, desenvolvem a capacidade de argumentação de suas ideias.

Cabe dizer que os incentivos por meio das interações dialógicas evidenciaram a participação nas respostas das senhoras e senhores aos questionamentos da equipe do LEM, em suas perguntas e justificativas das respostas, ou seja, argumentando suas ideias. Apresentamos um exemplo dessa interação em que se esperava que os participantes explicassem o que pensaram para chegar em uma solução. No Quadro 1, apresentamos uma tarefa trabalhada com a utilização da calculadora e, no Quadro 2, seguem observações do diário de campo sobre a mesma. Na Figura 6, podemos ver duas senhoras respondendo uma ficha utilizando uma calculadora.

Resolva as três primeiras expressões usando uma calculadora e escreva os resultados. Observe os resultados obtidos e escreva o resultado da 4- expressão sem usar a calculadora. Verifique depois sua resposta com a calculadora: a) $1 \times 8+1=$; b) $12 \times 8+2=$; c) $123 \times 8+3=$; d) $1234 \times 8+4=$

Quadro 1 - Tarefa matemática

Fonte: Elaborado pelos autores (2015).

Os participantes foram questionados sobre uma regularidade na disposição das expressões e:

Responderam que, na multiplicação, o fator 8 se mantem constante, enquanto o outro fator aumenta e que, na primeira linha, soma-se 1; na segunda 2, na terceira 3 e assim sucessivamente. Sobre o resultado de cada expressão, eles perceberam que, na primeira linha, dá 9; na segunda, 98; na terceira, 987; então, na quarta daria 9876. “E para obter como resultado 987654, qual deveria ser a expressão?”, questiona o pesquisador. Prontamente, uma senhora afirmou que seria preciso ter 123456 × $8+6$. Antes de ser questionada sobre sua conclusão, essa senhora respondeu que o número de algarismos do resultado deveria ser o mesmo número de algarismos que se deve multiplicar por 8, como 987654 tem seis algarismos seria preciso escrever o número 123456 e que, ao pensar na posição dessa expressão na sequência, ocuparia a sexta linha, consequentemente se deveria somar 6. Com a expressão pronta, todos conferiram na calculadora e verificaram que a resposta estava correta. (Diário de Campo, Conversas, 2015).

Quadro 2 - Diário de campo sobre tarefa com utilização da calculadora Fonte: Elaborado pelos autores (2015).

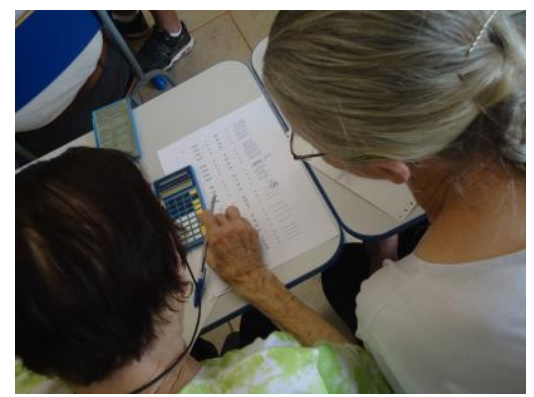

Figura 6 - Senhoras utilizando a calculadora para realizar tarefas da ficha. Fonte: Elaborado pelos autores (2015).

Assim como Freire (2001) afirma que estudar é um fazer crítico, criador e recriador, entendemos com Oliveira (2010) e Villani (2007), ao tratarem do ensino da Língua Inglesa para pessoas idosas, que o ambiente educativo promove uma reflexão sobre o processo de aprender para o idoso, resgatando sua confiança na potencialidade do próprio aprendizado. No Quadro 2 
é possível notar isso; afinal, a senhora não esperou que lhe pedissem para justificar seus argumentos, ela mesma o fez. Com o decorrer dos encontros, os participantes passaram a sentir, por si mesmos, a necessidade de justificar seus pontos de vista. Em sua fala, a senhora expõe a solução do problema e, em seguida, explica, a partir de sua análise da sequência, como chegou àquela conclusão. Ela defende sua solução, não a partir do resultado obtido na calculadora, mas após entender o comportamento dos termos que formavam a sequência, relacionando o resultado de cada expressão. Nesse sentido, podemos dizer que a abordagem pedagógica adotada na ação Conversas contribuiu para a criação de um ambiente em que

ensinar e aprender tem que ver com o esforço metodicamente crítico do professor de desvelar a compreensão de algo e com o empenho igualmente crítico do aluno de ir entrando como sujeito em aprendizagem, no processo de desvelamento que o professor ou professora deve deflagrar (FREIRE, 1998, p.134).

O uso dos recursos, entendidos como material didático, ou seja, "qualquer instrumento útil ao processo de ensino-aprendizagem” (LORENZATO, 2006, p. 18), tinha como intenção auxiliar os participantes a "questionar, observar padrões - resumindo, desenvolver uma atitude de investigação matemática” (PASSOS, 2006, p. 91). Escolhemos recursos já bem utilizados nas escolas, mas desconhecidos pela maioria dos participantes. A intenção foi oferecer um trabalho com uma Matemática com características atraentes. Por exemplo, em uma atividade em que foram propostos alguns problemas para serem realizados com calculadoras, antes de iniciá-la, uma das senhoras, sempre muito participativa, disse:

Não consegui fazer a atividade em casa. Liguei para minha nora, que mora em São Paulo e ela me explicou. Mas, antes de você começar, eu quero que fale sobre as funções da calculadora (Diário de Campo, Conversas, 2015).

Sendo assim, foram desenhadas, na lousa, as teclas da calculadora e discutimos, com a participação de todos, as funções de cada tecla. Os idosos falavam a função de uma tecla e a escrevíamos na lousa. As pessoas complementavam as ideias umas das outras e, quando alguém ficava em dúvida, questionava e sempre havia alguém para explicar de outra forma, diferente da que havia sido exposta. Ao final desse encontro, a senhora disse muito feliz: "Hoje foi muito bom!” (Diário de Campo, Conversas, 2015). Os participantes estavam à vontade para se expressar.

Sobre a participação das senhoras e senhores no grupo, ainda é importante ressaltar que ela influenciou compartilhamentos para além do espaço do LEM. Houve participantes que disseram ter sugerido, feito ou explicado as tarefas matemáticas com outras pessoas. Por exemplo, a Sra. Sueli (58) afirma durante a entrevista:

Uma das coisas que aprendi e brinquei com algumas pessoas foi aquele que monta o círculo e depois vai cortando e faz o mesmo com a faixa [de Moebius]. Eu fiz com pessoas amigas, com 
pessoas que eu estava dando aula [leciona aulas de artesanato na igreja que frequenta]. Eu fiz para descontrair. Usei as palavras de vocês, da forma que vocês fizeram e o pessoal gostou. Pedi para fazerem o cilindro e a faixa [de Moebius]. No cilindro, desenharam uma linha fora, depois eu pedi para elas fazerem dentro com outra cor e elas fizeram também. Eu perguntei para elas: "e, na faixa, o que vocês acham que vai acontecer, quando desenharmos?" e elas acharam que não iria dar certo. Então, pedi e desenharam [uma linha] de um lado e saía do mesmo lado. E, aí, elas viram que só tinha um lado a faixa. Eu passei com meu grupo de artesanato. Para descontrair. A gente não pode só todo tempo, duas, três horas ficar só bordando. Tem que ter um alongamento, alguma atividade, ou dá uma pausa e bate um papo de dez, quinze minutos. Elas gostaram muito, muito mesmo. Estou esperando aqui os meus sobrinhos para fazer com eles também (Ent, 2015).

O Sr. Roberto (77), ao tratar das atividades de que gostou, também faz questão de destacar que compartilha tarefas da ação Conversas com seus familiares:

Eu fiz aquela da coluna, linha... [Sudoku]. Eu marquei também as linhas. Um, dois, três, quatro, aqui, daquele lado [explicando como se resolve um Sudoku]. Tentei fazer bastante em casa também. Fiz aquele para colar também [faixa de Moebius], colar o papel aqui [mostra com uma folha de papel]. Eu cortava e colava também. Aí, sai o resultado direto, assim... só fazer direitinho. Aí fui recortando, recortando [com uma folha em mãos foi explicando como se faz a atividade da faixa de Moebius]. Aí, saiu uma coisa. E o pessoal [mulher e netos] lá em casa ficavam me vendo fazer e também queriam. Fazer essas coisas em casa chama a atenção. A gente pensa e fica mexendo ai o neto comenta: "deixa eu ver se eu faço". Aí vai tentar. Eu digo: "Tem que montar esses desenhos com essas peças aqui". Aqueles do quebra-cabeça chinês [Tangram]. Ele fica mexendo nas peças para ver se consegue: "uh consegui uma coisa" [consegue montar uma figura com o Tangram]. Aí vem a mulher e meu filho também, todo mundo tentando (Ent, 2015).

O compartilhamento de tarefas matemáticas, apontado pela Sra. Sueli (58) e pelo Sr. Roberto (77), traz evidências de um interesse em partilhar um conhecimento com o outro. Compartilhar saberes é uma forma de transmitir cultura, mostra uma preocupação com o bemestar atual e futuro de gerações vindouras, consequentemente, denota uma crença no futuro da humanidade e um compromisso com seu bem-estar (QUEROZ; NERI, 2005; REBELO; BORGES, 2009). E por falar em bem-estar, na próxima seção trataremos sobre contribuições da participação das senhoras e dos senhores na ação Conversas.

\section{Sobre contribuições da participação na ação Conversas}

Destacamos aqui as contribuições da participação na ação Conversas relacionadas ao bem-estar dos envolvidos ${ }^{3}$. Para isto, recorremos às entrevistas trazendo excertos das falas das senhoras e dos senhores que expressam: a) melhoria dos aspectos cognitivos; b) oportunidade de interação social; c) possibilidade de se conhecer novos assuntos relacionados com a

\footnotetext{
${ }^{3}$ É importante dizer que os profissionais do Proparki nos davam um retorno positivo sobre as tarefas matemáticas inseridas no AtivaMente. Eles diziam que os participantes comentavam com eles sobre as atividades desenvolvidas conosco.
} 
Matemática. Os participantes se mostraram, tanto nos encontros do grupo como durante as entrevistas, interessados em buscar meios para a melhoria de seus aspectos cognitivos e perceberam a ação Conversas como uma possibilidade para este fim. No que segue, trazemos dados que reforçam esse entendimento.

Um dos participantes, o Sr. Davi (67), ao comentar suas impressões sobre a ação Conversas, afirma: "Eu acho excelente para desenvolver a cabeça. Acho muito bom, principalmente, para esse pessoal que está começando com problemas [da doença de Parkinson]" (Ent, 2015). É possível perceber que, para ele, as tarefas matemáticas são importantes para as pessoas que começam a mostrar o avanço do Parkinson. Em relação a ele e a sua esposa, o Sr. Davi (67) considera que as tarefas matemáticas:

[...] abriram o nosso raciocínio. A gente começou a trabalhar com a mente. Entendeu? A, realmente, querer ver e tentar fazer, de ver pronto. Quando eu não consigo resolver alguma coisa, ou, quando você me pergunta alguma coisa assim muito rápida, dá uma batedeira aqui na cabeça. Sabe? É uma sensação difícil de explicar [...]. Para mim, estudar Matemática aqui com você é um pouco descômodo, porque mexe comigo. Entende? Mas o que conta é que é muito benéfica. Porque tem que movimentar a cabeça, porque é uma questão de raciocínio essas atividades (Ent, 2015).

A fala do Sr. Davi (67) reforça que um trabalho, envolvendo tarefas matemáticas, pode auxiliar na manutenção de "um arranjo mental apropriado para alcançar um objetivo futuro, [pois elas demandam] focalização atencional, gerenciamento de tarefas, planejamento e monitoramento na execução de um comportamento dirigido a objetivos" (KRISTENSEN, 2006). No recorte da fala desse senhor, é possível perceber um entendimento de que o fato de realizar tarefas matemáticas pode funcionar como uma atividade de estimulação cognitiva. Afinal, ele considera que sua participação na ação Conversas contribuiu para estimular seu raciocínio enquanto buscava encontrar soluções aos problemas matemáticos trabalhados.

Outro participante, o Sr. Luciano (68) considerou, inicialmente, difíceis algumas das tarefas matemáticas. Contudo, ele afirma: "vou tentar entender, porque eu vou tirar algum benefício disso" (Ent, 2015). Na entrevista, ele também se refere aos benefícios gerados por sua participação ao refletir sobre um assunto matemático, ao buscar a solução de um problema, ao compartilhar com os colegas as suas conclusões. Para ele, os benefícios estavam associados ao retardamento dos malefícios causados pela doença de Parkinson.

A Sra. Ju (60) considera relevante um trabalho envolvendo Matemática, principalmente para os colegas que têm mais dificuldade. Essa senhora sempre auxiliava os colegas no desenvolvimento das tarefas. Segundo ela, a ação Conversas:

É uma recordação do que foi aprendido tempos atrás e é bom para forçar a memória mesmo. Lógico, eu acho, tem gente que tem mais dificuldade, então eu não posso falar muito, não é!? Graças a Deus ainda consigo fazer bem essas contas e tudo, mas a gente percebe que tem gente 
com bastante dificuldade lá. E isso [tarefa de Matemática] ajuda bastante, mesmo continhas simples. Por isso que, às vezes, eu até evito falar resultado, porque eu penso: 'deixa para os outros falarem'. [...] Como minha memória, graças a Deus, ainda está um pouco mais ágil, deixo eles fazerem (Ent, 2015).

Em sua fala, a Sra. Ju (60) reforça que as "continhas" também contribuíram para estimular sua memória com a recordação de coisas vistas anteriormente. Ela era graduada em Matemática. Para os demais, ela considera que a tentativa de resolução das tarefas traz a mesma contribuição para o raciocínio. Essas “continhas”, mencionadas pela Sra. Ju (60), ocorreram em vários momentos. Por exemplo, no Bingo Matemático, os participantes precisavam fazer diversos cálculos mentais para determinar os números que eram sorteados.

A Sra. Sueli (58), ao comentar as tarefas matemáticas da ação Conversas, fala na mesma direção que a Sra. Ju (60). Ela entende que as tarefas contribuíram para estimular sua memória e acrescenta que elas a ajudavam a se concentrar e a se organizar em suas atividades cotidianas. Segundo esta senhora:

A gente, às vezes, fica sem lembrar algumas coisas, sem memorizar. Então, com a ajuda de vocês, a Matemática tem ajudado. Eu memorizo bem números. Pelo fato de estar sempre utilizando telefone, números diversos e o Bingo [Matemático] ajuda muito. Resumindo, todas as atividades da Matemática são boas. Por exemplo, aquelas de blocos de madeira [Blocos Lógicos] foi excelente [...]. Tem algumas coisas que você passa a pensar em relação ao que você ouviu e então a gente acaba também colocando no dia-a-dia da gente. Isso melhora a qualidade da vida da gente. No memorizar, no se concentrar, se organizar (Ent, 2015).

É possível que a relação, feita pela Sra. Sueli (58), das tarefas matemáticas com sua vida cotidiana, tenha sido potencializada por nossa abordagem pedagógica durante a ação Conversas. Diferentemente do desenvolvimento de estratégias automatizadas, os idosos eram convidados a explorar diversas soluções para as tarefas propostas. Por meio de tentativas, eles elaboravam estratégias para abordar os problemas e, não raro, continuavam explorando as tarefas em casa. No caso das atividades com o Tangram, o Sr. Roberto (77), por exemplo, além de desenvolver as tarefas em casa, desenhava suas soluções para comentá-las durante os encontros com o grupo do LEM. Nesse processo, o Sr. Roberto (77) se mostrava persistente na busca de soluções para as tarefas matemáticas, estimulando suas capacidades cognitivas.

Tal estímulo ocorreu durante todos os encontros da ação Conversas. Neles, os participantes realizaram cálculos mentais como, por exemplo, somar os números contidos em cada linha e em cada coluna de um Quadrado Mágico para verificar os resultados; resolver expressões para descobrir o número do bingo matemático; resolver expressões matemáticas de tarefas como "Eu tenho...Quem tem...?”. Além disso, com o Tangram e os Blocos Lógicos eles percebiam maneiras diferentes de fazer combinações para montar as figuras desejadas. Sentiam muito prazer em realizar essas tarefas, não raro eram bastante competitivos para dizer a resposta 
em primeiro lugar. Avaliaram positivamente todas as tarefas em relação às contribuições cognitivas, tais como a contribuição para a atenção, capacidade de observação e consequentemente com a lembrança das coisas. Em relação à sua capacidade de evocar informações, a Sra. Sueli (58 anos) considera que as atividades matemáticas foram importantes:

Então, dentro das atividades que vocês aplicam, eu gosto do Tangram, do Bingo, da Faixa [de Moebius]. E assim, essas atividades puxam pela memória. A gente, às vezes, fica sem lembrar algumas coisas, sem memorizar. Então, com a ajuda de vocês, a Matemática tem ajudado [...] no memorizar, no se concentrar, se organizar. [...] Eu mentalizava, mas começava a realizar [uma atividade] e não terminava. Então, nisso [as tarefas matemáticas] tem ajudado muito. $\dot{E}$ importante o pessoal da Matemática também na nossa turma. Na mobilidade, ensina muito: desenvolver, começar e terminar. Eu tinha essa dificuldade e vi que não era somente eu, os meus colegas de turma de Parkinson também tem (Ent, 2015).

Consideramos que tarefas matemáticas podem contribuir como estímulo e/ou manutenção de habilidades cognitivas. Nesse sentido a Sra. Sueli (58) entende que sua participação na ação Conversas a auxiliou a se concentrar e a se organizar no desenvolvimento de tarefas cotidianas. A fala dessa senhora sugere que a realização de atividades, envolvendo Matemática, pode contribuir, assim como o treino cognitivo apontado por Yassuda et al. (2006), para que os participantes reflitam e organizem suas atividades cotidianas. Afinal, resolver uma atividade do dia a dia pode-se assemelhar com a resolução de uma tarefa de Matemática em que se busca entender o problema, levantam-se e testam-se ideias/estratégias para resolvê-lo.

O Sr. Luís (64) entende que as atividades matemáticas contribuem para sua vida, já que "fica mais ativo, com uma mente, uma memória melhor. Presta mais atenção nas coisas" (Ent, 2015). A fala desse senhor corrobora o entendimento de Baraldi (2001) ao sugerir que trabalhar com Matemática possibilita que pessoas na terceira idade continuem progredindo no raciocínio lógico-matemático, um elemento essencial para a manutenção da memória com coerência e organização. Já Martorell et al. (2009) destacam que a utilização de uma abordagem investigativa na resolução de problemas matemáticos favorece não apenas o desenvolvimento de habilidades científicas e a produção de novos conhecimentos pelos idosos, mas propicia uma maior satisfação em relação às suas próprias expectativas cognitivas.

Ao refletirem sobre as atividades desenvolvidas na ação Conversas, os senhores e as senhoras entenderam que a participação lhes trouxe contribuições como melhorar o raciocínio, lembrar de assuntos aprendidos anteriormente, concentrar-se, prestar mais atenção nas coisas e ser mais ativo. Isso está de acordo com ideias, como em Apóstolo et al. (2011), de que a estimulação pode melhorar a condição cognitiva de idosos. Esses pesquisadores aconselham a implementação de atividades nesse sentido como um componente do cuidado de idosos em um contexto comunitário. Por isso, entendemos que trabalhos com tarefas matemáticas, como na 
ação Conversas, também podem ser utilizados como forma de estímulo cognitivo a pessoas idosas.

Cabe ressaltar que, além da interação com outras pessoas idosas, eles interagiam com os monitores durante as atividades. A oportunidade de interação social se mostrou importante nas falas dos entrevistados. A Sra. Teresa (80) comenta sobre o ambiente da ação Conversas comenta: Eu gosto muito de ir lá [ação Conversas], eu gosto demais. [...]. É tudo muito bom. [...]. Estou aprendendo com vocês. É muito bom. E todo mundo trata a gente bem lá (Ent, 2015).

O Sr. Roberto (77) trata sobre a animação: “Gostei mesmo, porque, na sala, é tudo muito animado. É muito gostoso estar ali. Não tem nada que eu possa falar assim: 'aquilo ali não gostei muito não" (Ent, 2015). Teodoro (2006) considera que a frequência, de muitos dos idosos, em espaços educativos, tem a ver com o interesse em: preencher o tempo livre, se distrair, conhecer outras pessoas, ampliar amizades, dentre outros. É muito pouco provável que alguém, independentemente da idade, se não for obrigado por algum motivo, queira participar de um grupo em que não seja "gostoso estar ali".

A Sra. Ju (60) reforça esta ideia, pois segundo ela: "Eu gosto muitíssimo [de ir à Unesp], porque têm pessoas que não são do meu convívio no dia a dia. Ah, eu também gosto de conversar sobre Matemática. Não é!? É bom estar lá e eu ajudo o pessoal que fica perto de mim. Eu fiz Matemática, então eu gosto de ajudar quem está com dificuldade” (Ent, 2015). Essa senhora se sentia valorizada ao poder auxiliar os colegas. Esta maneira de agir, da Sra. Ju (60), era comum no ambiente da ação durante a realização de uma tarefa. Embora contassem com o apoio da equipe do LEM quando tinham dificuldade em algo, entre os participantes também havia uma vontade em ajudar aquele que estivesse com dificuldades. Atitudes como essa, viabilizadas numa dinâmica de trabalho de pequenos grupos, com o uso de materiais manipuláveis, contribuíam para tornar o ambiente um momento prazeroso de interação.

Espaços voltados à educação na terceira idade podem estimular os aspectos cognitivos dos participantes e podem ser uma oportunidade de interação social. Além disso, eles podem ser uma possibilidade de conhecer novos assuntos relacionados com a matemática. Em nosso caso, sugerimos assuntos matemáticos que, de acordo com os sujeitos entrevistados, viabilizaram novas aprendizagens. Exemplo disso é um excerto da entrevista do Sr. Davi (67), em que ele fala sobre a possibilidade de abordar assuntos matemáticos, que até então desconhecia: "Gosto de vir à Unesp, porque entro em contato com coisas que não são do meu cotidiano. [Sobre as atividades de Matemática] Eu gosto, porque fiz algumas coisas que nunca tinha feito como o Bingo [Matemático], o Tangram e outras coisas também” (Ent, 2015). A participação na ação Conversas, como evidenciado pelo Sr. Davi (67), possibilitou a discussão 
de assuntos novos que se mostraram de seu interesse. Isso também reflete a vontade de aprender coisas novas, o que Alves (2007) constatou em um grupo de senhoras que retornam à escola na terceira idade.

A Sra. Teresa (80) reforça o interesse em participar da ação para aprender novos assuntos: "Eu quero aprender tudo o que vocês ensinam nas aulas. Tudo o que vocês quiserem ensinar, eu vou querer aprender" (Ent, 2015). No mesmo sentido, a Sra. Sueli (58) afirma que as atividades estão interessantes, mesmo não sugerindo algo que gostaria de aprender, ela pontua: "Eu acho que as coisas de Matemática que estamos aprendendo com vocês são muito boas. Se é para dizer algo, eu digo que vocês podem continuar assim, com coisas interessantes para a gente aprender" (Ent, 2015).

$\mathrm{Na}$ ação Conversas os membros mostraram uma postura aberta à aprendizagem, confirmando a ideia de que "onde quer que haja mulheres e homens, há sempre o que fazer, há sempre o que ensinar, há sempre o que aprender" (FREIRE, 1998, p. 90). A Sra. Teresa (80), por exemplo, disse durante a entrevista que recorria às netas, pois necessitava de auxílio para as tarefas matemáticas que realizava em casa. Mas isto também poderia ser um meio para se aproximar delas, com assuntos distintos de seu cotidiano. Algo semelhante foi relatado por Coura (2007) acerca de idosos que descreveram uma intensificação nas relações familiares com o retorno à escola. "Essa intensificação das relações familiares ocorre pela necessidade de auxílio para fazer algum trabalho, de carona dos filhos ou mesmo pelos assuntos gerados pelos conteúdos escolares" (COURA, 2007, p. 104).

A maioria dos participantes da ação Conversas teve que deixar de estudar para se dedicar ao trabalho, o que era importante para o sustento da família. Mesmo diante das adversidades, essas pessoas evidenciaram uma vontade em continuar a aprender. Em outras palavras, voltaram sua intencionalidade para as tarefas propostas. Como destaca Skovsmose (2011), a aprendizagem, como uma forma de ação, é um processo cheio de intenções e motivos. Dessa forma, consideramos oferecer condições para conhecer novos assuntos, uma contribuição relevante da ação Conversas.

É importante dizer que a ação Conversas também possibilitou a inserção de idosos em um ambiente diferente, o da universidade. Isso contribuiu com a sensação de bem-estar, ao viabilizar canais de comunicação de assuntos diferentes daqueles aos quais os participantes estavam habituados, como a Matemática, com pessoas da própria geração e de outras gerações, como os integrantes do grupo do LEM e do PROPARKI. Scagion (2018) aponta para a importância de criação de ambientes que permitam estes encontros intergeracionais. Além disso, a participação em atividades educativas, como defendido por Pereira (2009, p. 172), 
"favorece o envolvimento ativo com atividades e pessoas, a integração social e os investimentos pessoais e, assim, leva a um envelhecimento bem-sucedido".

Na mesma direção, segundo a pesquisadora Freire (2000), uma velhice satisfatória depende da interação do indivíduo em transformação, vivenciando uma sociedade que também está em transformação. Para a referida autora, determinadas estratégias, como o cultivo de novos hábitos mentais e o aperfeiçoamento de habilidades sociais, podem favorecer essa satisfação na velhice. Nesse sentido, consideramos que a ação Conversas viabilizou tal desenvolvimento de novos hábitos mentais, a partir da realização de tarefas matemáticas. Igualmente, ela possibilitou interações entre os envolvidos, como pode ser notado a partir dos trechos das entrevistas com os idosos citados anteriormente.

Diante disso, concordamos com Freire (2000) ao entender que um envelhecimento bemsucedido se relaciona a um bem-estar psicológico, que leva em conta uma relação de qualidade com os outros, ou seja, uma relação calorosa, satisfatória e verdadeira; que se preocupa com o bem-estar alheio; em que se é capaz de relações empáticas e afetuosas. Isto requer, igualmente, um crescimento pessoal contínuo. Pode-se considerar o fato de participar de um grupo de diálogo sobre assuntos matemáticos como algo que revela uma abertura dos participantes a outras experiências.

Os nossos resultados corroboram o fato de que atividades educativas contribuem para que indivíduos idosos aproveitem, positivamente, esta fase da vida e, até mesmo, para que possam superar os desafios que muitas vezes lhes são impostos. Conforme destacado pela pesquisadora Freire (2000), as relações sociais compõem um conjunto de elementos importantes para o bem-estar psicológico e para uma melhor qualidade de vida. Os participantes relataram seu interesse em estar com os colegas do grupo. Havia senhoras e senhores que se conheceram naquele espaço, pois moravam em regiões distintas da cidade. Participar do grupo também viabilizou conhecer os integrantes do LEM e do PROPARKI. Por esse motivo, defendemos, com Schenkel (2009), a participação de idosos em atividades socioeducativas visando diminuir a exclusão dos mais velhos.

Para além de promover uma convivência social, com o preenchimento do tempo livre, a ação Conversas possibilitou reflexões sobre assuntos matemáticos. Essas interações, com outras pessoas e com assuntos distintos do cotidiano, favorecem o desenvolvimento da autoestima e a manutenção da independência, que são elementos constitutivos da qualidade de vida (ALVES, 2007; COURA, 2007; PEREIRA, 2009; SOUZA et al., 2009; VELASCO, 2006; VILLANI, 2007). 


\section{Considerações finais}

Neste artigo discutimos a participação ativa das senhoras e dos senhores na realização de tarefas matemáticas. É relevante destacar que esta atividade não intencionou substituir outras possíveis ações com o público idoso. Não foi nosso objetivo comparar com outros assuntos que também favorecem o cognitivo. A nossa intenção foi a de compreender como atividades envolvendo Matemática podem se constituir como uma possibilidade para pessoas na terceira idade.

A participação dos idosos na ação se revelou pelo interesse demonstrado em comentar o assunto trabalhado; a persistência para realizar as tarefas por conta própria; a possibilidade de argumentar as próprias ideias; e os compartilhamentos para além do espaço da universidade. Além disso, ressaltamos as contribuições dessa participação relacionadas ao bem-estar dos envolvidos como a melhoria dos aspectos cognitivos; a oportunidade de interação social; e a possibilidade de conhecer novos assuntos relacionados à Matemática.

Atribuímos tais resultados a adoção da concepção de Extensão Universitária como uma possibilidade de comunicação com outros setores da sociedade. Comunicação em que se entende que os homens aprendem entre si e, por isso, produzem conhecimentos em colaboração uns com os outros. O entendimento da extensão como uma forma de comunicação implicou em elaboração de tarefas matemáticas que pudessem promover o diálogo e a participação por meio de experimentações e manuseio de materiais.

Nesse sentido, entende-se que um diálogo com idosos, envolvendo assuntos matemáticos, poderá ser mais atraente se planejado com a utilização de recursos condizentes com suas necessidades. Por exemplo, uma ficha com uma história sobre algum assunto matemático, com letras muito pequenas, pode ser um obstáculo para a leitura de quem tenha problemas de visão. Os recursos são uma parte importante e os resultados podem ser melhores, se houver a oportunidade para que os senhores e as senhoras do grupo expressem suas opiniões e dúvidas, assim como suas conclusões sobre as atividades desenvolvidas.

Para um trabalho educativo, envolvendo Matemática com pessoas idosas, consideramos importante ter uma equipe compromissada em promover um ambiente de ensino e de aprendizagem por meio de: interações com os participantes (fazer perguntas constantemente sobre o assunto matemático trabalhado); estímulos à interação entre eles (trabalho em grupo); experimentações com recursos diferenciados (Faixa de Moebius, Tangram, Blocos Lógicos, calculadoras, Bingo Matemático, dentre outros); organização do tempo, dentre outros aspectos relevantes para a organização de um encontro agradável a todos. Por fim, esperamos que esse 
estudo possa contribuir para discussões sobre um trabalho, envolvendo Matemática com pessoas idosas, tanto para a área acadêmica, com reflexões a respeito dessa possibilidade por meio da Extensão Universitária, quanto para outros setores da sociedade que estejam preocupados com o desenvolvimento de atividades para essa população.

\section{Referências}

ALRØ, H.; SKOVSMOSE, O. Diálogo e Aprendizagem em Educação Matemática. Tradução de Orlando de A. Figueiredo. 2. ed. Belo Horizonte: Autêntica, 2015. (Coleção Tendências em Educação Matemática).

ALVES, E. M. S. O idoso na sala de aula: um novo ator. 2007. 123 f. Dissertação (Mestrado em Educação) - Universidade Católica de Brasília, Brasília, 2007.

APÓSTOLO, J. L. A. et al. Efeito da estimulação cognitiva em idosos. Revista de Enfermagem Referência, Coimbra, v. 3, n. 5, p. 193-201, dez. 2011.

BARALDI, I. M. Oficinas Matemáticas: uma experiência com a terceira idade. In: ENCONTRO NACIONAL DE EDUCAÇÃO MATEMÁTICA, 7., 2001, Rio de Janeiro. Anais... Rio de Janeiro: SBEM, 2001. Não paginado.

BODGAN, R. C.; BIKLEN, S. K. Investigação qualitativa em educação: uma introdução à teoria e aos métodos. Porto, Portugal: Editora Porto, 2010.

BOUFLEUER, J. P. Dicionário Paulo Freire. Belo Horizonte: Autêntica, 2010.

BRANCO, P. G. Envelhecimento e educação de idosas: processos e desenvolvimentos singulares. 2007. Dissertação (Mestrado em Gerontologia) - Pontifícia Universidade Católica de São Paulo, São Paulo, 2007.

CACHIONI, M.; NERI, A. L. Educação e Velhice bem-sucedida no contexto da terceira idade. In: NERI, A. L.; YASSUDA, N. S. (Org.). Velhice bem-sucedida: aspectos afetivos e cognitivos. Campinas: Papirus, 2004. p. 29-49.

CACHIONI, M.; PALMA, L. S. Educação permanente: perspectiva para o trabalho educacional com o adulto maduro e idoso. Tratado de Geriatria e Gerontologia, 2. ed. Rio de Janeiro: Guanabara Koogan, [S.l: s.n.], 2006.

COURA, I. G. M. A terceira idade na educação de jovens e adultos: expectativas e motivações. 2007. 134 f. Dissertação (Mestrado em Educação) - Faculdade de Educação, Universidade Federal de Minas Gerais, Belo Horizonte, 2007.

DIAS, F. A. Qualidade de Vida de Idosos e Participação em Atividades Educativas Grupais. 2010. 139 f. Dissertação (Mestrado em Atenção à Saúde) - Programa de Pós-Graduação em Atenção à Saúde, Universidade Federal do Triângulo Mineiro, Uberaba, 2010.

DUARTE, R. Entrevistas em pesquisas qualitativas. Revista Educar, Curitiba, n. 24, p. 213-255, 2004.

FREIRE, P. Pedagogia da autonomia: saberes necessários à prática educativa. São Paulo: Paz e Terra, 1998. (Coleção Leitura). 
mai./ago. 2001.

Carta de Paulo Freire aos professores. Revista Estudos Avançados, São Paulo, v. 15, n. 42,

Pedagogia do oprimido. 50. ed. Rio de Janeiro: Paz e Terra, 2011.

FREIRE, P.; FAUNDEZ, A. Por uma pedagogia da pergunta. Revisão técnica e tradução do texto de Antonio Faundez, Heitor Ferreira da Costa. 7. ed. rev., ampl. e atual. São Paulo: Paz e Terra, 2011.

FREIRE, S. A. Envelhecimento bem-sucedido e bem-estar psicológico. In: NERI, A. L.; FREIRE, S. A. (Org.). E por falar em boa velhice. Campinas: Papirus, 2000.

FREITAS, E. V. D.; PY, L. Tratado de Geriatria e Gerontologia, 2. ed. Rio de Janeiro: Guanabara Koogan, [S.l: s.n.], 2006.

GOLDEMBERG, M. A bela velhice. 2. ed. Rio de Janeiro: Record, 2013.

IBGE. Ministério do Planejamento, Orçamento e Gestão. Diretoria de Pesquisas. Projeções da População: Brasil e Unidades da Federação. Série Relatórios Metodológicos, v. 40. Rio de Janeiro: IBGE, 2013.

. Ministério do Planejamento, Desenvolvimento e Gestão. Diretoria de Pesquisas. Coordenação de População e Indicadores Sociais. Tábua completa de mortalidade para o Brasil - 2015: breve análise da evolução da mortalidade no Brasil. Rio de Janeiro: IBGE, 2016.

. Ministério do Planejamento, Desenvolvimento e Gestão. Diretoria de Pesquisas. Projeções da População: Brasil e Unidades da Federação Revisão 2018. Séries Relatórios Metodológicos, v. 40. 2 ed. Rio de Janeiro: IBGE, 2018a.

. Ministério do Planejamento, Desenvolvimento e Gestão. Diretoria de Pesquisas. Pesquisa Nacional por Amostra de Domicílios Contínua: características gerais dos domicílios e dos moradores 2017. Rio de Janeiro: IBGE, 2018b.

KRISTENSEN, C. H. Funções executivas e envelhecimento. In: PARENTE, M. A. D. M. P. (Org.). Cognição e Envelhecimento. Porto Alegre: Artmed, 2006. p. 97 - 111.

LARA, C. R. S. A educação do idoso como fator de melhoria de sua saúde: um estudo sobre uma experiência da ESF Machado Fagundes em Cascatinha - Petrópolis. 2010. 115 f. Dissertação (Mestrado em Educação) - Universidade Católica de Petrópolis, Petrópolis, 2010.

LORENZATO, S. (org.). O laboratório de ensino de matemática na formação de professores. Campinas: Autores Associados, 2006.

LIMA, L. F. Conversas sobre matemática com pessoas idosas viabilizadas por uma ação extensionista. 2015. 186 f. Tese (Doutorado em Educação Matemática) - Universidade Estadual Paulista (Unesp), Rio Claro, 2015.

LIMA, L. F.; PENTEADO, M. G. Barricada, bandeiras, escola, jóquei-clube: atividades matemáticas para pessoas na terceira idade. Revista Em Extensão, v. 12, n. 2, p. 109-127, 2013.

MARTORELL, I. et al. Inquiry-Based learning for older people at a University in Spain. Educational Gerontology, [s.1.], v. 35, p. 712-731, 2009.

MAPA DA DESIGUALDADE 2016. Rede Nossa São Paulo, 2016. Disponível em: https://www.nossasaopaulo.org.br/arqs/mapa-da-desigualdade-completo-2016.pdf. Acesso em: 28 abr. 2018. 
NERI, A. L. Palavras-chave em Gerontologia. Campinas: Alínea, 2001.

OLIVEIRA, H. F. À flor da (terceira) idade: crenças e experiências de aprendizes idosos de língua estrangeira (inglês). Dissertação (Mestrado em Linguística Aplicada) - Universidade de Brasília, Brasília, 2010.

PASSOS, C. L. B. Materiais manipuláveis como recursos didáticos na formação de professores de matemática In: LORENZATO, S. (org.). O laboratório de ensino de matemática na formação de professores. Campinas: Autores Associados, 2006.

PEREIRA, E. T. A terceira idade na universidade aberta: navegando, buscando, aprendendo em um mar sem fim. 2009. Tese (Doutorado em Linguística Aplicada)- Pontifícia Universidade Católica de São Paulo, São Paulo, 2009.

PEREIRA, J. M. M. A escola do riso e do esquecimento: idosos na Educação de Jovens e Adultos. Educ. foco, Juiz de Fora, v. 16, n. 2, p. 11-38, set. 2011/fev. 2012.

PINHEIRO, G. A. D. Educação e Envelhecimento: atividade intelectual na terceira idade. 2009. 105 f. Dissertação (Mestrado em Educação) - Programa de Pós-Graduação em Educação, Universidade Estadual de Maringá, Maringá, 2009.

PONTE, J. P. D.; BROCARDO, J.; OLIVEIRA, H. Investigações Matemáticas na sala de aula. 3. ed. Belo Horizonte: Autêntica, 2015. (Coleção Tendências em Educação Matemática).

QUEROZ, N. C; NERI, A. L. Bem-estar psicológico e inteligência emocional entre homens e mulheres na meia-idade e na velhice. Revista Psicologia: Reflexão e Crítica, [online], v. 18, n. 2, pp. 292-299. 2005.

REBELO, P. V; BORGES, G. F. Contributos para o estudo do desenvolvimento do adulto: reflexões em torno da generatividade. Revista Práxis Educacional, Vitória da Conquista, v. 5, n.7, pp. 97-114, jul. 2009.

SANTOS, A. T. D.; SÁ, M. A. A. S. De volta às aulas: ensino e aprendizagem na terceira idade. In: NERI, A. L.; FREIRE, S. A. (Org.). E por falar em boa velhice. Campinas: Papirus, 2000. p. 91100 .

SCAGION, M. P. Representações sociais de pessoas idosas sobre matemática. $2018.98 \mathrm{f}$. Dissertação (Mestrado em Educação Matemática) - Instituto de Geociências e Ciências Exatas, Universidade Estadual Paulista, Rio Claro, 2018.

SCHENKEL, C. C. Uso das tecnologias de informação e comunicação no processo de socialização do idoso. 2009. Dissertação (Mestrado em Educação) - Programa de Pós-Graduação em Educação, Universidade de Passo Fundo, Passo Fundo, 2009.

SIEDLER, M. J. A tecnologia educativa do cinedebate como forma de desenvolvimento da gerontocultura. 2006. Dissertação (Mestrado em Enfermagem) - Programa de Pós-Graduação em Enfermagem, Universidade Federal de Santa Catarina, Florianópolis, 2006.

SILVA, G. H. G., LIMA, L. F. Educação matemática na terceira idade: uma experiência com atividades manipulativas. In: ENCONTRO PAULISTA DE EDUCAÇÃO MATEMÁTICA, 12, Birigui, 2014. Anais... Birigui: Sociedade Brasileira de Educação Matemática Regional São Paulo, 2014, p. 939-947.

SKOVSMOSE, O. Cenários para investigação. Boletim de Educação Matemática (BOLEMA), Rio Claro, v. 13, n. 14, p. 66-91, 2000. 
An invitation to critical mathematics education. Rotterdam: Sense Publishers, 2011.

SOUZA, P. A. D. et al. Oficinas de estimulação cognitiva para idosos com demência: uma estratégia de cuidado na enfermagem gerontológica. Revista Brasileira de Ciências do Envelhecimento Humano, Passo Fundo, v. 6, n. 3, p. 362-372, 2009.

TEODORO, M. F. M. UnATI/UERJ: uma proposta de educação permanente para o cidadão idoso. 2006. 175 f. Dissertação (Mestrado em Educação) - Faculdade de Educação, Universidade Católica de Petrópolis, Rio de Janeiro, 2006.

VANDEnBos, G. R. Dicionário de Psicologia da APA. Tradução de Daniel Bueno, Maria A. V. Veronese, M. C. Monteiro. Porto Alegre: Artmed, 2010.

VELASCO, C. Aprendendo a envelhecer: a luz da psicomotricidade. São Paulo: Phorte, 2006.

VILLANI, F. L. longevidade no aprendizado de línguas: acrescentando vida aos anos e não anos a vida. 2007. 258 f. Tese (Doutorado em Linguística) - Programa de Pós-Graduação em Linguística Aplicada, Pontifícia Universidade Católica de São Paulo, São Paulo, 2007.

YASSUDA, M. S.; et al. Treino de memória no idoso saudável: benefícios e mecanismos. Psicologia: Reflexão e Crítica, v. 19, n. 3, p. 470-481, 2006. 